REVISTA ECONOMÍA

Vol. 67, N. ${ }^{\circ}$ I05 (mayo 2015) I5-27.

\title{
MARX Y EL EXTRACTIVISMO
}

\author{
DAVID CHÁVEZ \\ Universidad Central del Ecuador
}

Recepción manuscrito: 4 de diciembre de 2014

Aceptación versión final: 21 de febrero de 2015

\begin{abstract}
RESUMEN En los actuales debates sobre desarrollo y «extractivismo» en el Ecuador hay una tendencia evasiva en relación con una posible interpretación marxista de este tema. Esto se debe a la hegemonía en este campo de discusión de ciertas interpretaciones provenientes del postestructuralismo, el poscolonialismo y el neoestructuralismo. Sin embargo, subyace ahí una pregunta fundamental: ¿Puede la crítica de Marx contribuir a la interpretación de la cuestión del «extractivismo»? Este es el punto de partida de este artículo. En esencia, se propone que esa crítica puede contribuir a superar ciertas limitaciones importantes en aquel campo de debate.
\end{abstract}

PALABRAS ClaVe Marxismo, capital, renta, extractivismo, desarrollo.

ABSTRACT On the current debate about development and «extractivism» in Ecuador there is a trend that dismisses any possible of marxist interpretation about this subject. This is an effect of the hegemony in this field of discussion of some perspectives that came from postestructuralism, postcolonialism and neoestructuralism. However, the underlying question is: Can Marx's critique contribute to the interpretation of "extractivism»? This is the point of departure of this paper. In essence, it proposes that the Marx's critics can contribute to overcome of some of the most important limitations in that field of debate.

KEYWORDS Marxism, capital, ground rent, extractivism, development.

CODIFICACIÓN JEL B14, C10, O13, P10, Q50.

\section{INTRODUCCIÓN}

En el debate sobre extractivismo y desarrollo hay una clara «toma de distancia» respecto de la crítica teórica desarrollada por Marx. Más que una discusión detenida y rigurosa prevalece la intención de reducir o distorsionar las formulaciones de Marx dejándolas como tesis demasiado elementales o simplistas. Esto conduce a una serie de inevitables malentendidos sobre el carácter de la reproducción capitalista y sus efectos sobre las condiciones ecológicas. Es decir, las perspectivas predominantes en este campo del debate abordan el problema del capitalismo desconociendo o minimizando la crítica de Marx, lo cual produce serias limitaciones en la comprensión de la naturaleza del capital. Este artículo propone una discusión de 
varios de los elementos centrales de la crítica de Marx que parecen haber sido malentendidos u omitidos por posdesarrollistas y neodesarrollistas. En este sentido, este estudio inicia intentando mostrar que no hay tanta novedad en los planteamientos sobre el extractivismo y que precisamente en el ámbito del marxismo y el neomarxismo se ha desarrollado una sólida interpretación sobre esto. Luego pasamos a un examen de varias de las categorías centrales de la crítica de Marx que aportarían una mejor comprensión del «metabolismo social-natural»: naturaleza, trabajo, reproducción social, relaciones sociales de producción y renta de la tierra.

\section{EL DEBATE MARXISTA SOBRE EL EXTRACTIVISMO}

En una entrevista, el presidente Rafael Correa sostuvo que el marxismo-leninismo no menciona en ninguna parte una crítica contra el extractivismo (Correa, 2013). En respuesta, los académicos Eduardo Gudynas (2013) y Joan Martínez Alier (2013), inscritos en las corrientes del postextractivismo y la ecología política respectivamente, señalaron lo contrario. Mientras Gudynas afirma que el tránsito hacia el postextractivismo se inscribe en la idea marxista de buscar «alternativas a la producción», Martínez Alier, considera que los conceptos de «acumulación originaria» y «metabolismo social» demostrarían la oposición de Marx al extractivismo. Esta discusión llama mucho la atención porque el debate entre ambas posiciones se ha caracterizado por una compartida «toma de distancia» respecto de la teoría marxista y, en ocasiones, por una abierta contradicción con ella.

Precisamente Gudynas y Martínez Alier representan esa perspectiva. Gudynas (2011, p. 47) asume que el pensamiento de Marx está inscrito en lo que denomina «la ideología del progreso y la modernidad» y Martínez Alier piensa que Marx no considera los intercambios de flujos materiales y energéticos de la sociedad y la naturaleza (Martínez Alier, 1995, pp. 262-264; Martínez Alier y Schlüpmann, 1997, pp. 270, 318-319), para ambos allí estarían los límites de la crítica de Marx. Para Enrique Leff, en cambio, el positivismo de la teoría del valor de Marx desterró del campo de la economía a la naturaleza, al quitarle la condición de fuente de valor que tenía en otras escuelas de pensamiento como la fisiocrática y trasladar esa condición al trabajo (Leff, 2004, pp. 1-43). Otras de las reflexiones sobre extractivismo y desarrollo sencillamente omiten cualquier discusión con el marxismo (Acosta, 2009; 2011; Acosta, Martínez, \& Sacher, 2013). Y finalmente hay otras en las que conceptos de tradición marxista como capitalismo, acumulación de capital, «acumulación por desposesión», están presentes, pero como meros conceptos descriptivos y no como categorías explicativas, por lo que terminan siendo nociones indefinidas, ambiguas, poco claras. Esto ocurre porque estos conceptos se hallan inscritos en una matriz teórica enteramente diferente de corte más bien postestructuralista y post o decolonial (Prada Alcoreza, s.f.; Svampa, 2011; Lander, 1996). ${ }^{1}$ También es observable la influencia de ciertos elementos provenientes del desarrollismo cepalino en relación a conceptos como «modelo primario-exportador», «intercambio desigual» o «dependencia» (Acosta, 2009; Martínez Alier, 1998; Prada Alcoreza, s.f.). ${ }^{2}$

En este contexto, queda una pregunta irresuelta en términos teóricos: $i$ Qué interpretación puede hacerse de la noción de «extractivismo» desde la crítica de Marx? Las dificultades 
de una aproximación de este tipo provienen, en mi opinión, de que el objeto teórico «extractivismo» no es el que preocupa a Marx, su objeto es otro sustancialmente distinto: el capital. Los postextractivistas o postdesarrollistas se equivocan al poner la discusión en un plano teórico que es distinto a aquel sobre el que Marx trabaja. El dilema de un Marx extractivista o antiextractivista es - en todo rigor- un falso dilema; Marx no es ni una ni otra cosa, su crítica pone en el centro a su teoría del plusvalor como fundamento del capital, es decir el complejo proceso de producción que subordina al trabajo y logra reproducirse mediante su explotación.

Ahora bien, más allá del alejamiento explícito o implícito, estas posiciones evidencian una aproximación superficial o equivocada frente al debate que el tema ha suscitado en el campo del marxismo. Es necesario, por tanto, recuperar algunos elementos básicos de ese debate de modo que sea posible contrastarlo con aquello que para tanto para postextractivistas como para neodesarrollistas aparece como «descubrimientos». En este sentido, es indudable que el debate que gira en torno a la explicación marxista del extractivismo se inicia con el trabajo de Bunker, quien desde un enfoque neomarxista analiza la dinámica de las actividades económicas extractivas en la Amazonía brasileña (Bunker, 1988). ${ }^{3}$ Quizá lo más relevante de sus planteamientos tiene que ver con la distinción que hace entre «modos de producción»y «modos de extracción» (pp. 22-58). De acuerdo a Bunker, los supuestos teóricos utilizados por Marx, en especial la generalización del capital como forma social, limitan seriamente la posibilidad de utilizar la ley del valor como fundamento teórico para explicar la situación de economías periféricas centradas en la exportación; en particular, el límite más significativo tendría que ver con que la ley del valor de Marx omite o minimiza el intercambio de materia y energía de alta intensidad que las actividades extractivas generan entre naturaleza y sociedad, lo cual hace imposible dimensionar las pérdidas por el agotamiento de los recursos naturales y por tanto se necesita una categoría distinta, «modo de extracción», para explicar ese proceso (pp. 11-15 y 20-22).

La crítica de Volk (1986) al trabajo de Bunker señala que este autor cae en un error teórico que lo pone en tensión con la crítica de Marx. Este consiste en que termina por inscribirse en la tradición que habla del «valor de la naturaleza»; es decir, aquella que considera a la naturaleza como creadora de valor; lo cual contrasta con el fundamento de las teorías del valor y del plusvalor de Marx que atribuyen esa capacidad exclusivamente al trabajo (pp. 1431-1432). De acuerdo a Volk, con esta debilidad teórica en el núcleo de su planteamiento de los «modos de extracción», esta tesis de Bunker sencillamente pierde piso, de modo que las características que atribuye a las economías extractivistas, en contraste con las productivas, no son más que formas específicas de los rasgos que asumen las economías exportadoras sobreespecializadas (pp. 1432-1435). Por otro lado, Volk considera que uno de los problemas centrales que tiene la propuesta de Bunker radica en que no distingue con claridad las categorías de valor y valor de uso en Marx, esto le llevaría a confundir el valor de uso que sí tiene la naturaleza con el valor que sería un resultado eminentemente social. ${ }^{4}$

En mi opinión el debate actual sobre extractivismo en América Latina halla una significativa correspondencia con las posiciones de Bunker, claro llevando esas posiciones a una especie de «destilación» postestructuralista-postcolonialista o neoestructuralista según sea 
el caso. Sobre la base de estas consideraciones me parece que las posibilidades interpretativas derivadas de la crítica de Marx tienen relevancia para el debate sobre el extractivismo. En particular, harían posible superar las limitaciones derivadas de la impronta postestructuralista-postcolonial y neoestructuralista que hegemonizan el debate. El alcance de este artículo no hace posible una discusión minuciosa, pero en lo que sigue señalo algunos de los elementos que deberían considerarse al tratar de incluir a Marx en el actual debate sobre extractivismo y desarrollo, a partir de una aproximación a varios de los textos de la crítica de la economía política desarrollada por Marx.

\section{NATURALEZA Y TRABAJO}

Llevada hacia sus fundamentos teóricos, la discusión sobre el extractivismo se vincula con la idea de su incomprensión de las condiciones naturales. La severa inconsistencia que contiene esta afirmación ha sido demostrada suficientemente por Foster (2000) y Burkett (2006), quienes han dejado establecida con claridad la importancia que tiene el problema de la naturaleza en Marx. Es imprescindible considerar también el trabajo de Alfred Schmidt (1977) en el que explica con singular rigurosidad que la noción de naturaleza dista mucho de ser periférica en la argumentación de Marx; su propuesta pone énfasis en la relación mediada entre sociedad y naturaleza, en otras palabras, la imposibilidad de reducir la realidad a la mera existencia física de la materia, la decisiva importancia que en Marx tiene la objetividad de las relaciones sociales. ${ }^{5} \mathrm{El}$ marco en el que Marx hace esta reflexión tiene que ver precisamente con su teorización sobre el «metabolismo social».

Ahora bien, la comprensión del metabolismo entre «lo social» y «lo natural» señalado por Marx, supone una formulación muy precisa que - tal como afirma Smith (2008) — no puede ser captada como mero «intercambio» e «interacción», requiere ser pensada como una relación dialéctica e histórica, es decir, supone una contradicción que genera sucesivas transformaciones del mundo material, por lo que el proceso determinante de esa relación es la producción - y especialmente en el trabajo- como queda claramente establecido en la Introducción a los Grundrisse (Marx, 2006; Marx, 1983). ${ }^{6}$ Neil Smith propone comprender esta dialéctica a partir de las nociones de "primera naturaleza» $\mathrm{y}$ "segunda naturaleza» referidas por Marx. Dado que el metabolismo social-natural es un proceso contradictorio, hay una especie de «solución social» a la contradicción que lleva a una permanente modificación de la "primera naturaleza» — el mundo material no alterado por la actividad humana- que la convierte en «segunda naturaleza» —el mundo material transformado por la actividad humana-. La expresión que adquiere esta dialéctica en términos históricos sería la producción del excedente; pero, como señala la tradición marxista, esto conlleva la diferenciación social en clases sociales y la opresión de unas por otras en función del control del excedente (Smith, 2008, pp. 63-69). Siguiendo la tesis de Smith se puede decir que la forma más adecuada de comprender la compleja dialéctica del «mundo objetivo» en Marx, solo puede encontrar sentido en la idea de que el «mundo de los objetos o valores de uso» corresponde a la materialización de las relaciones sociales del producción. Este es lo que podría considerarse el sustento ontológico de la teoría del plusvalor de Marx. De este 
modo, la tesis de la ecología política acerca de los flujos de materia y energía parece sugerir una minimización del carácter dialéctico de esa relación y del carácter específicamente social que determina las formas concretas de esos flujos.Para Marx el trabajo - y más precisamente la fuerza de trabajo- es una «fuerza natural» que se opone a otras fuerzas naturales, de modo que por medio del trabajo el ser humano modifica el mundo «natural» al tiempo que modifica su propia «naturaleza humana»; el sentido específico de la dialéctica sociedad-naturaleza deriva de allí (Marx, 1975, pp. 215-216; 1962, p. 192; 1979, pp. 9-10; 1987, pp. 15-16). Asimismo, Marx define a la naturaleza como «fuerza productiva no producida»; es decir, su concepción dista de reducir la naturaleza a mera fuente de recursos, el concepto de fuerza productiva es más amplio e involucra justamente el uso de energía y la dinámica biofísica concreta que establece límites a la producción capitalista que tiende a sobrepasarlos de modo destructivo.

Es por ello que la valoración que hace Marx del desarrollo de las fuerzas productivas por el capitalismo, antes que una fascinación «ilustrada» y positivista, es, cuando menos, ambigua. Esto porque identifica con toda claridad que esas fuerzas productivas pueden dejar de serlo y adquirir un carácter destructivo. En el primer tomo de El capital, al referirse a la relación entre la gran industria y la agricultura, señala: «La producción capitalista [...] no desarrolla la técnica y la combinación del proceso social de producción sino socavando, al mismo tiempo, los dos manantiales de toda riqueza: la tierra y el trabajador» (Marx, 1975, pp. 612-613; 1962, pp. 529-530).

Si esto deja poco espacio para las dudas, ¿a qué se debe la confusión de sus detractores post y neoextractivistas?, ¿en qué se sustenta la extendida idea de que Marx no toma en cuenta la naturaleza o le asigna un rol secundario? La respuesta parece apuntar, en primer lugar, al hecho de que Marx no confunde riqueza (producción de valores de uso) con valor económico, cosa que curiosamente sus críticos hacen con frecuencia. Es decir, la materialización del trabajo en valores de uso responde a una lógica específica de la vida social, mientras que su contenido de trabajo social necesario, que corresponde a la dimensión del valor, corresponde a otro registro de la vida social, el que tiene que ver propiamente con las relaciones sociales de producción. En consecuencia, para Marx la naturaleza no forma valor, pero lejos de constituir un límite en su enfoque esta formulación es esencial en su crítica al capital; lo que Marx demuestra es que la dominación capitalista no proviene de ninguna condición natural, sino de condiciones propiamente sociales; lo que está poniendo en cuestión es la idea que naturaliza la ganancia capitalista o la renta, convirtiéndolas en cualidades intrínsecas de la naturaleza o los medios de producción. Pero más que eso, la razón teórica para esto es que la condición de posibilidad que hace posible el intercambio capitalista es el contenido de trabajo abstracto de las mercancías, es esto lo que puede cuantificarse y puede crear una esfera específica de intercambios gobernados por una estricta dimensión cuantitativa. Cualquier objeto natural pasa a ser social y, más específicamente, se convierte en mercantil cuando es mediado por el trabajo, cuando se transforma en objeto social.

En contraste con esto, tesis como la de la «mercantilización de la naturaleza» resultan inconsistentes, la naturaleza en sí misma no puede volverse mercancía, para llegar a algo así se requiere la mediación del trabajo. Se establece una relación dialéctica que no puede 
perderse de vista, la materia natural (o energía) es transformada por el trabajo al tiempo que este no puede existir como pura abstracción, requiere de esa materialidad; es más, tal como lo concibe Marx, el trabajo creador de valor (trabajo abstracto) es energía. Desde este punto de vista, la presión sobre los recursos naturales y todas sus consecuencias se explican por la expansión de las necesidades de creación de plusvalor propias del capital y esto implica revisar cómo esa expansión se relaciona con este proceso central del capitalismo. Un ejemplo clásico: la importancia del oro radica en la función social que cumple en la sociedad capitalista, su condición de medio de intercambio, lo cual no excluye otros usos posibles; pero su valor se relaciona con la cantidad de trabajo que contiene el proceso de su extracción.

En segundo lugar, es visible una noción fetichizada de la naturaleza y de la técnica, en ella la comprensión de ambas aparece como «objetividad pura» entendida como «objetualidad», por lo que el encuentro entre el «objeto técnico» y el «objeto natural» es inevitablemente destructivo, es esto lo que conduce a una noción muy extendida sobre el extractivismo, a saber, definir la dinámica social de una actividad económica en función de su instrumentalidad productiva; por otra parte, la consideración fetichizada se enmarca plenamente en lo que N. Simth denomina «ideología de la naturaleza»; es decir la concepción burguesa que separa tajantemente sociedad- naturaleza, asignando a «lo natural» una forma no-social «pura»; lo cual imposibilita comprender a la naturaleza como socialmente producida (Smith, 2008, pp. 10-48).

En tercer lugar, lo cual explica lo anterior, se trata de una interpretación paradójicamente "productivista», es decir que - por efecto de su visión fetichizada- no logra ver en el «mundo de los objetos- la expresión de relaciones sociales de producción, consideración está que es crucial para comprender el sentido que la objetividad tiene en la crítica de Marx, por tanto es una interpretación que se detiene en un erróneo aislamiento de las fuerzas productivas, atribuyendo a estas últimas las características que corresponden más bien a las relaciones sociales de producción. De modo que antes que una «superación de Marx», el reclamo por la supuesta poca importancia atribuida al «intercambio metabólico» entre naturaleza y sociedad presente en Marx, se convierte en un retroceso cientificista hacia formas de materialismo anteriores a Marx; en este sentido, la centralidad de los flujos de energía y materiales bien puede considerarse como una versión contemporánea del «materialismo de la materia» esbozado por Feuerbach, debido a la escasa atención prestada al carácter que esos flujos adquieren en función de su pertenencia a una forma histórica concreta de ordenamiento de las relaciones sociales de producción. ${ }^{7}$

La simplificación de estos aspectos o su omisión nos pueden permitir decir que en los distintos análisis sobre extractivismo hay una débil discusión con la crítica de Marx. Es por este motivo que las referencias al capitalismo terminan siendo inocuas y no alcanzan a dar cuenta de toda la complejidad que reviste este planteamiento de Marx. ${ }^{8}$ Bajo el prejuicio del «economicismo» de Marx se pasa por alto el hecho de que su crítica intenta justamente poner en cuestión el economicismo de la economía política y para ello esboza una comprensión enteramente nueva de lo que con exactitud podría entenderse como «reproducción material de la vida social», concepto mucho más amplio y complejo. Uno de los resultados más críticos de todo esto es la anulación del fundamento ontológico que representa el trabajo en Marx. 


\section{REPRODUCCIÓN SOCIAL, CAPITAL E INDUSTRIAS EXTRACTIVAS}

En El capital Marx hace una definición sobre lo que entiende por actividades extractivas. En el marco de su exposición sobre el proceso de trabajo - capítulo V del libro I- señala que este se realiza sobre un «objeto de trabajo» (Arbeitsgegenstand) determinado, pero distingue dos tipos: uno que puede llamarse «objeto general» (allgemeine Gegenstand) y que es ofrecido directamente por la naturaleza sin mediación de trabajo alguno como la tierra (que incluye el agua), los peces, etc.; y otro que corresponde a lo que propiamente se denominan como «materias primas» (Rohmaterial), aquellos objetos que sirven de base a la producción pero son producto de procesos de trabajo previo (Marx, 1975, pp. 216-217; 1962, p. 193). Este riguroso y detenido tratamiento de los conceptos le sirve de base para determinar que todas las ramas industriales trabajan sobre materias primas, pero hace una excepción: la «industria extractiva». Para Marx, solo en el caso de esta última el proceso de trabajo ocurre sobre aquel «objeto general», solo en estos casos la naturaleza es directamente «objeto de trabajo». Por esa razón Marx considera como industria extractiva a la minería, como es lógico suponer, pero también a la caza o la pesca; así mismo, sobre la agricultura precisa que esta solo puede ser parte de esta categoría cuando corresponde a la roturación y cultivo de «tierras vírgenes»; es decir, cuando se trata de tierras que no han sido - en el más estricto de los sentidos-cultivadas previamente (Marx, 1975, p. 220; 1962, p. 196).

Una primera cuestión que debe tenerse en cuenta a partir de esta formulación sobre la industria extractiva es que ella no se inscribe en la perspectiva «economicista» largamente atribuida a Marx; hace parte de lo que sería su teorización sobre el «proceso de reproducción social» entendido como un esquema general que subyace a todas las formas históricas, esa dimensión de la vida social a la que Bolívar Echeverría llama «forma natural» de la reproducción social que corresponde a su estrato «transhistórico y supraétnico» (Echeverría, 1984, 1998, 2010). No obstante, el problema teórico que se plantea Marx es que esta idea general no es suficiente para la explicación del carácter específico de las formas históricas, en particular, del régimen capitalista de producción (Marx, 1975, p. 215; Marx, 1982, pp. 244-245; 2006, p. 38). Esto, porque es indispensable tener en cuenta la categoría de relaciones sociales de producción para comprender el carácter de las formas históricas concretas. Y esta es una cuestión fundamental en el posible aporte de la crítica de Marx a la discusión sobre el extractivismo.

A partir de sus consideraciones sobre el proceso general de reproducción social es posible señalar que la especificidad propia de un tipo de actividades económicas no define al régimen de producción. Más allá de lo que cierto marxismo vulgarizado y sobre todo buena parte de sus críticos supone, lo central de la crítica de Marx no radica en las fuerzas productivas, sino en las relaciones de producción. Son estas las que imprimen el carácter concreto que adquiere una forma histórica determinada (Marx, 2006; 1983). Es por ello que -dice Marx en El capital- la perspectiva abstracta del «metabolismo social» se limita al hombre como un concepto general, ya que en este plano teórico no cuentan las relaciones que los hombres establecen entre sí para producir. Es más, anota que el capitalismo no tiene diferencia alguna con otras formas sociales en este plano general, que en ese nivel es indiferente si el proceso de trabajo se realiza para el esclavista, el señor feudal o el capitalista (Marx, 1975, p. 223). Las implicaciones teóricas de esto son de una importancia extraordinaria, en las formas históricas concretas la relación 
hombre-naturaleza no puede explicarse por sí sola, el carácter que esta asume proviene de las relaciones que los hombres establecen para dar forma a su socialidad. En el debate que analizamos es este fundamento teórico el que se halla suprimido o puesto en cuestión. Las formulaciones que se hacen sobre el extractivismo tienen como sustento el presupuesto teórico de una relación sociedad-naturaleza no mediada, lo cual en realidad corresponde al nivel fenomenológico, al modo en que las relaciones sociales se expresan en el plano de la «apariencia».

Quizá lo más interesante en este contraste entre la crítica postdesarrollista y la crítica de Marx es que la supresión conceptual de las relaciones de producción desplaza el problema al campo estrictamente instrumental. Solo mediante esta operación teórica es posible extender el concepto de la técnica extractiva de ciertas actividades económicas a todo el régimen de producción. Ese problema se torna más complejo si se tiene en cuenta que - siempre siguiendo a Marx - la técnica adquiere significación social y política si es entendida como parte de la organización social de la producción.

\section{CAPITAL Y TRABAJO: LA IMPORTANCIA DE LAS RELACIONES SOCIALES DE PRODUCCIÓN}

Sobre la base de la categoría de relaciones de producción, Marx pone en el centro de la sociedad capitalista la relación capital-trabajo, la cual es explicada a partir de su teoría del plusvalor. El objetivo del régimen capitalista es la producción de plusvalor y su apropiación para la reproducción del capital. De entre las muchas consecuencias teóricas que esto tiene, conviene subrayar algunas que pueden ser de interés para nuestra discusión.

Para empezar se debe tener en cuenta lo relacionado con el «lugar específico» del modo de producción capitalista. Las dos primeras secciones de El capital buscan cuestionar una tesis central de la economía política clásica, a saber: la reproducción del capital ocurre en el ámbito de la circulación. El problema fundamental es que lo propiamente capitalista consiste en el efecto multiplicador del capital, su capacidad de incrementarse, proceso casi milagroso si se lo mira desde la superficie de los fenómenos económicos. En concreto, el capital es tal cosa porque es lanzado a la dinámica económica, cumple un ciclo determinado y retorna incrementado. Marx retoma la tesis «circulatoria», la analiza rigurosamente y muestra que es imposible ese incremento ocurra en la esfera de los intercambios mercantiles; este tiene lugar en otra parte, se origina en un espacio distinto: la producción. No obstante, si bien su génesis se halla en otro lugar, solo puede realizarse en la circulación, de ahí su complejo proceso social; al respecto dice Marx: «[el] capital, por ende, no puede surgir de la circulación, y es igualmente imposible que no surja de la circulación. Tiene que brotar al mismo tiempo en ella y no en ella» (Marx, 1975, p. 202; 1962, p. 180). En definitiva, la circulación es vital para que el plusvalor entre en el ciclo de metamorfosis del capital, el plusvalor sale de la producción con la forma mercancía, esta necesariamente debe transformarse en dinero para reiniciar el ciclo, si no lo hace, el proceso de reproducción se interrumpe.

La categoría fundamental aquí es la de reproducción, el capital solo puede existir socialmente en un proceso reproductivo incesante. Y vinculado con esto se halla el proceso de acumulación de capital que se relaciona con lo que Marx define como reproducción ampliada (Marx, 1975, pp. 713-729; 1962, pp. 605-617). Esto implica además una serie de 
consecuencias centrales para la crítica al orden social establecido por el capital que se resumen en la tendencia a la baja de la cuota de ganancia y la alteración de la composición orgánica del capital que esa tendencia ocasiona (Marx, 1977, pp. 269-341; 1964, pp. 221-241). Esta perspectiva general vuelve del todo insuficiente la caracterización de una situación histórica concreta a partir de criterios que se limitan a la descripción de una actividad económica específica como las industrias extractivas, peor aún atribuir a esas características los efectos que provienen de la dinámica concreta del capital y no necesariamente de la particularidad de esas actividades (Gudynas, 2011, p. 385; Acosta, Martínez, \& Sacher, 2012; Acosta, 2011, p. 117). De lo que se trataría entonces es de desentrañar cómo se encuentran interrelacionadas las distintas actividades específicas y cuál es su relación efectiva con la dinámica de acumulación. Así, dependiendo de esas relaciones las actividades extractivas pueden ocasionar o no una mayor presión sobre los recursos naturales y la población, pero esas presiones no son necesariamente intrínsecas a dichas actividades; de igual modo, pueden existir actividades de producción industrial o «cognitiva» que presionen muchísimo sobre esas condiciones como efecto de su rol en el proceso específico de reproducción del capital.

\section{LA CUESTIÓN DE LA RENTA}

El esquema general que hemos recuperado de Marx nos habla de lo que denomina el «capital en general»; el paso teórico hacia el conjunto tripartito salario-ganancia-renta supone dirigir la mirada hacia la forma en que el plusvalor se distribuye entre las distintas formas concretas del capital y los propietarios no capitalistas. Para la discusión sobre el extractivismo es necesario prestar atención a la renta de la tierra. De entrada hay que decir que para Marx la propiedad de la tierra involucra el control sobre ciertas "porciones del planeta» e incluye todos los recursos relacionados con ella como el agua, los recursos minerales, los bosques, etc. (Marx, 1981, pp. 793-796). No podemos profundizar la discusión, pero es necesario tener en cuenta que la renta permite la «valorización de la propiedad territorial», es decir, constituye una parte de la plusganancia o ganancia extraordinaria capitalista que debe entregarse al propietario, esta ganancia supone un excedente sobre la tasa media de ganancia del capital social global (Marx, 1981, pp. 825-833); pero lo central es que la tierra por sí sola no puede producir esa ganancia.

Sin embargo, es muy importante decir que la renta no constituye solamente un "pago por derechos de propiedad», Marx afirma al respecto: «[nada] se resuelve con el poder jurídico de estas personas [los propietarios de la tierra] de hacer uso y abuso de porciones del planeta» (Marx, 1981, p. 794); lo que explica el problema de la renta es su relación con la reproducción del capital. La renta proviene de una condición básica: la posibilidad de monopolizar un recurso natural determinado que genera una productividad del trabajo más alta que la media y por tanto un plusvalor más alto que el promedio general. Este tipo de ganancia es la que obtiene un capitalista individual por las ventajas que le permiten alcanzar costos de producción más bajos en relación con la generalidad de los otros capitalistas. Esto es posible por dos factores determinantes: las condiciones naturales y las tecnológicas; el control que pueda tener de ellas hacen posible ese comportamiento del capital. Es por esta 
razón que el monopolio sobre esas condiciones de producción es decisivo en el proceso de reproducción capitalista. ${ }^{9}$ De todos modos, hay que insistir, se debe evitar la confusión de que debido a esto la naturaleza tienen valor, ella favorece la producción de valor porque incrementa la productividad del trabajo, pero sin la mediación de este aquellas condiciones ventajosas sencillamente no alcanzan existencia económica.

Otro aspecto a considerarse es que la inversión de capital sobre esas condiciones hace posible que el capital «se fije en la tierra», lo que obliga a ciertas distinciones importantes. De acuerdo a Marx, esas inversiones transforman la tierra en "capital tierra» y corresponden a las mejoras técnicas temporales como la fertilización y abono de la tierra, o permanentes como la construcción de infraestructura (Marx, 1981, p. 797). Esto hace que la tierra, así intervenida, se transforme en capital fijo. De ahí se deriva que cuestionar de modo general la construcción de infraestructura, por ejemplo, como un mecanismo para la acumulación de capital, nos dice muy poco sobre lo que eso significa en términos precisos; para lograr un acercamiento más exacto a este problema es indispensable comprender la lógica espacial del capital. ${ }^{10}$

Por otra parte, esta compleja relación entre la renta y el capital plantea la necesidad de problematizar dos cuestiones fundamentales. Por un lado, el tema del control estatal sobre la renta y su rol como redistribuidor de la plusganancia entre los distintos capitalistas o sectores del capital, ${ }^{11}$ por otro, el significado de transformar la «matriz productiva» hacia la «economía del conocimiento». Es indispensable tener en cuenta que esta última no puede entenderse sino como una forma de renta que se comporta de manera semejante a la renta de la tierra: la renta tecnológica. Según Echeverría, esta forma de renta habría terminado por subordinar totalmente a la renta de la tierra en el capitalismo contemporáneo y permitirá un absoluto control de los monopolios tecnológicos que deja muy poco margen para la competencia; por lo que las condiciones de subordinación de las economías desarrolladas difícilmente pueden superarse por esa vía; por el contrario esa situación de las formas de la renta capitalista, profundizarían la dependencia de la renta de la tierra en formaciones sociales subdesarrolladas (Echeverría, 2010, pp. 36-40). Conviene analizar en el mismo sentido las propuestas alternativas que centran su atención sobre las actividades de servicios como el turismo. Descifrar estos intricados mecanismos es uno de los retos conceptuales y políticos que plantea un intento por comprender el extractivismo desde la crítica de Marx.

Estas breves notas no buscan en absoluto agotar el tema, apenas intentan dejar esbozadas ciertas líneas, no todas por supuesto, para una aproximación al debate sobre extractivismo recuperando el enfoque crítico de Marx. Evidentemente este intento requiere de una discusión mucho más detenida y de trabajos concretos de investigación que permitan ampliar o cuestionar los alcances que los aspectos señalados puedan tener. Debemos insistir: lamentablemente el diálogo con esta perspectiva teórica de las distintas posiciones en el debate sobre extractivismo está ausente. Por lo tanto, este es un camino que ni siquiera se ha iniciado. Entre los temas que pueden cobrar un sentido distinto si se lleva a cabo este ejercicio están cuestiones como las del modelo primario-exportador o extractivista, el concepto abstracto y general de desarrollo, el uso del concepto de «acumulación por desposesión»; y principalmente las posibles alternativas. 


\section{NOTAS}

1 Un ejemplo muy interesante de esto puede verse en el trabajo de Brand y Wissen en el que buscan caracterizar lo que llaman «modo de vida imperial» en referencia al capitalismo contemporáneo (Brand y Wissen, 2013). Aunque el problema planteado sugiere otra cosa, la ausencia de una discusión con el campo conceptual del marxismo es patente y sigue el carácter descriptivo que hemos señalado, en el único intento por el uso de las categorías desarrolladas por Marx, en particular la de plusvalor, yerran el tiro y confunden plusvalor relativo con intensificación del trabajo (pp. 452-453). Es absolutamente ilustrativo, por lo demás, que en el volumen en que se halla el texto de Brand y Wissen, que dice hablar de capitalismo y que tiene algo más de quinientas páginas, la categoría de plusvalor aparezca una sola vez. 2 De entre las revisiones más interesantes de las nociones estructuralistas «clásicas» destaca la de Martínez Alier, quien sobre la base de su tesis del intercambio de flujos materiales y energéticos entre sociedad y naturaleza deriva la propuesta de un «intercambio ecológico desigual» $\mathrm{o}$ «deuda ecológica» entre países desarrollados y subdesarrollados (Martínez Alier, 1998, pp. 143-151). Por otro lado, Grigera \& Álvarez (2013) anotan que en los enfoques postextractivistas es posible encontrar la influencia del estructuralismo cepalino, la teoría de la dependencia y el marxismo; aunque no es el lugar para discutir esto in extenso, me parece que es necesario distinguir la función conceptual de cada corriente, me parece que el primero de ellos se ubica en el registro de la fundamentación teórica y conceptual, mientras que tanto la teoría de la dependencia como el marxismo tienden a cumplir esa condición descriptiva, que no explicativa, de la que he hablado.

3 De manera explícita este trabajo, en el debate ecuatoriano, aparece mencionado solo por Ortiz (2011). Este hecho llama enormemente la atención dadas las coincidencias que pueden encontrarse en las posiciones postextractivistas y las tesis de Bunker.

4 Es importante decir que la tesis de Bunker resulta sumamente problemática dado que reproduce el argumento de economistas burgueses. Con anterioridad a Bunker, Perelman advierte que Paul Samuelson sostiene la misma idea sobre la ley del valor y su límite para entender los flujos materiales y energéticos (Perelman, 1975).

5 Es recomendable revisar el segundo de los ensayos publicados en la obra mencionada, «La mediación histórica de la naturaleza y la mediación natural de la sociedad», en el que Schmidt se aproxima a lo que podemos llamar la «mediación dialéctica» existente entre sociedad y naturaleza a partir del examen de la mercancía efectuado por Marx. Por lo demás, es significativo que Martínez Alier, en su intento por demostrar la «ceguera» marxista, ni siquiera mencione, peor aún discuta, este importante trabajo.

6 Es esto lo que escapa al análisis de Alfred Schmidt como señala correctamente Smith (2008, pp. 32-44). 7 Ese materialismo «contemplativo», no social, es el que Marx critica en Feuerbach en sus conocidas tesis (Marx, 2011; 1978).

8 Quizá se debe aclarar que cuando decimos «dar cuenta» no nos referimos a asumir sin más la crítica de Marx, sino a discutirla y -de ser el caso- proponer un enfoque teórico distinto.

9 En el ámbito del análisis marxista la cuestión de la renta ha sido de los temas más complejos y discutidos. Caligaris (2014) hace un bien documentado recorrido por este debate señalando dos ámbitos de discusión: el origen de la renta de la tierra y el carácter específico de la renta diferencial de tipo II. Ambas se relacionan con el rol del plusvalor de los trabajadores agrícolas y del capital agrícola en la renta respectivamente. 10 El desarrollo teórico más interesante al respecto es el que han propuesto Harvey (2006) y Smith (2008). En lo esencial, sostiene que el vínculo contradictorio entre producción y realización es esencial para comprender la geografía del capital (p. 416); el desenvolvimiento de esa contradicción implica una cuestión fundamental: el capital necesita fijarse materialmente, es decir, espacialmente (p. 415) en su forma productiva, mientras que en su forma circulatoria necesita desprenderse de esa fijación espacial.

11 El trabajo de Iñigo Carrera sobre el carácter del capitalismo en Argentina aporta algunas consideraciones de significativa importancia. En particular, señala varios mecanismos que permiten al Estado disputar la renta de la tierra con los terratenientes tales como impuestos, devaluaciones, subsidios, entre otros (Iñigo Carrera, 2007). 


\section{REFERENCIAS}

Acosta, A. (2009). La maldición de la abundancia. Quito, Ecuador: Abya-Yala.

Acosta, A. (2011). Extractivismo y neoextractivismo: Dos caras de la misma maldición. Quito, Ecuador: Abya-Yala / Fundación Rosa Luxemburg.

Acosta, A., Martínez, E., y Sacher, W. (2013). Salir del extractivismo: una condición para el Sumak Kawsay. Propuestas sobre petróleo, minería y energía en Ecuador. En M. Lang, C. López y A. Santillana (Comp.), Alternativas al capitalismo/colonialismo del siglo XXI (pp. 307-382). Quito, Ecuador: Abya-Yala.

Brand, U. y Wissen, M. (2013). Crisis socioecológica y modo de vida imperial. Crisis y continuidad de las relaciones sociedad-Naturaleza en el capitalismo. En M. Lang, C. López y A. Santillana (Comp.), Alternativas al capitalismo/colonialismo del siglo XXI (pp. 445-484). Quito, Ecuador: Abya-Yala.

Bunker, S. G. (1988). Underdeveloping the Amazon: Extraction, Unequal Exchange, and the Failure of the Modern State. Chicago, USA: University of Chicago Press.

Burkett, P. (1999). Marx and nature: a red and green perspective. Nueva York, USA: St. Martin's Press.

Burkett, P. (2006). Marxism and Ecological Economics. Toward a Red and Green Political Economy. Boston, USA: Brill.

Caligaris, G. (2014). Dos debates en torno a la renta de la tierra y sus implicancias para el análisis de la acumulación de capital en la Argentina. Razón y Revolución, (27), 59-79.

Correa, R. (2013, febrero 21). Con Argentina tenemos la misma visión en lo político. Página 12. Recuperado de http://www.pagina12.com.ar/diario/elmundo/4-214315-2013-02-21.html.

Echeverría, B. (1984). La «forma natural» de la reproducción social. Cuadernos polítcos , (41), 33-46.

Echeverría, B. (1986). El discurso crítico de Marx. México DF, México: Era.

Echeverría, B. (1998). Valor de uso y utopía. México DF, México: Siglo XXI.

Echeverría, B. (2010). Renta tecnológica y «devaluación» de la naturaleza. En Modernidad y blanquitud. México DF, México: Era.

Foster, J. B. (2000). Marx's Ecology. Materialism and Nature. Nueva York. USA: Monthly Review Press.

Grigera, J., y Álvarez, L. (2013). Extractivismo y acumulación por desposesión. Un análisis de las explicaciones sobre agronegocios, megaminería y territorio en la Argentina de la posconvertibilidad. Theomai, (27-28), 80-97.

Gudynas, E. (2011). Debates sobre el desarrollo y sus alternativas en América Latina: Una breve guía heterodoxa. En M. Lang, y D. Mokrani (Comp.), Más allá del desarrollo (pp. 21-53). Quito, Ecuador: Abya Yala / Fundación Rosa Luxemburg.

Gudynas, E. (2013, febrero 7). Hoy, en América Latina, Marx ¿sería extractivista? América Latina en movimiento. Recuperado de http://alainet.org/active/61470

Harvey, D. (2006). The Limits to Capital. Londres, Gran Bretaña: Verso.

Iñigo Carrera, J. (2007). La formación económica de la sociedad argentina. Vol. 1. Renta agraria y deuda externa. 1882-2004. Buenos Aires, Argentina: Imago Mundi.

Lander, E. (1996). El dogma del progreso universal. En E. Lander (Ed.), El límite de la civilización industrial (pp. 5-10). Caracas, Venezuela: Facultad de Ciencias Económicas y Sociales UCV.

Leff, E. (2004). Racionalidad ambiental. La reapropiación social de la naturaleza. México DF, México: Siglo XXI. 
Martínez Alier, J. (1995). De la economía ecológica al ecologismo popular. Montevideo, Uruguay: Nordan comunidad / Icaria.

Martínez Alier, J. (1998). Curso de economía ecológica. México DF, México: PNUMA.

Martínez Alier, J. (2013, abril 20). Marx, el ecologismo y Correa. La Jornada. Recuperado de http:// www.jornada. unam.mx/2013/04/20/politica/021a2pol.

Martínez Alier, J., y Schlüpmann, K. (1997). La ecología y la economía. Bogotá, Colombia: FCE.

Marx, K. (1962). Das Kapital. Kritik der politischen Ökonomie. Erster Band. Buch I: Der Produktionprozeß des Kapitals (MEW-Tomo 23). Berlín, Alemania: Dietz.

Marx, K. (1963). Das Kapital. Kritik der politischen Ökonomie. Zweiter Band. Buch II. Der Zirkulationsproze $\beta$ des Kapitals (MEW-Tomo 25 ed.). Berlín: Dietz.

Marx, K. (1964). Das Kapital. Kritik der politischen Ökonomie. Dritter Band. Buch III. Der Gesamtsproze $\beta$ der kapitalistischen Produktion (MEW-Tomo 25 ed.). Berlín, Alemania: Dietz.

Marx, K. (1975). El capital. Crítica de la economía política. Libro primero. El proceso de producción del capital. Mexico DF, México: Siglo XXI.

Marx, K. (1976). El capital. Crítica de la economía política. T II. El proceso de circulación del capital. México DF, México: Siglo XXI.

Marx, K. (1977). El capital. Crítica de la economía política. Libro tercero. El proceso global de la producción capitalista. México DF, México: Siglo XXI.

Marx, K. (1978). These über Feuerbach. En K. Marx, \& F. Engels, Werke (3), pp. 5-7.

Marx, K. (1979). Crítica del Programa de Gotha. Pekín, China: Ediciones en lenguas extranjeras.

Marx, K. (1983). Grundrisse der Kritik der politischen Ökonomie (MEW-Tomo 42). Berlín, Alemania: Dietz.

Marx, K. (1987). Kritik des Gothaer Programms. En K. Marx, y F. Engels, Werke (19), 11-32.

Marx, K. (2006). Introducción general a la crítica de la economía política / 1857. México DF, México: Siglo XXI.

Marx, K. (2011). Tesis sobre Feuerbach. En B. Echeverría, El materialismo de Marx (pp. 109-121). México DF, México: Itaca.

Marx, K., y Engels, F. (1974). La ideología alemana. Barcelona, España: Grijalbo.

Ortiz, P. (2011). Capitalismo extractivo, minería y derechos: ¿Pueden cohabitar? Íconos. Revista de Ciencias Sociales (39), 11-23.

Perelman, M. (1975). Natural Resources and Agriculture under Capitalism: Marx's Economic Model. American Jorunal of Agricultural Economics , 57(4), 701-704.

Prada Alcoreza, R. (s.f.). Cartografías histórico-políticas. ISSUU. Recuperado de http://issuu.com/raulpradaalcoreza /docs/extractivismo

Schmidt, A. (1977). El concepto de naturaleza en Marx. Madrid, España: Siglo XXI.

Smith, N. (2008). Uneven Development. Nature, Capital, and the Production of Space. Georgia, USA: The University of Georgia Press.

Svampa, M. (2011). Extractivismo neodesarrollista y movimientos sociales. ¿Un giro ecoterritorial hacia nuevas alternativas? En M. Lang, y D. Mokrani (Comps.), Más allá del Desarrollo. Quito, Ecuador: Abya-Yala.

Volk, R. W. (1986). Comment on Bunker. American Journal of Sociology, 91(6), 1431-1437. 
